East African Medical Journal Vol. 86. No. 12 December 2009

PRESSURE ULCERS PRESENTATION AND MANAGEMENT AT KENYATTA NATIONAL HOSPITAL AND SPINAL INJURY HOSPITAL

F.W. Nangole, MBChB, MMed (Surg), Consultant Plastic and Reconstruction Surgeon, Kenyatta National Hospital, P.O. Box 20723 - 00202, Nairobi, Kenya, S.O. Khainga, MBChB, MMed (Surg), Senior Lecturer, Division of Plastic Surgery, and J. Kiboi, MBChB, MMed (Surg), Lecturer, Division of Neurosurgery, Department of Surgery, College of Health Sciences, University of Nairobi, P.O. Box 19676-00202, Nairobi, Kenya

Request for reprints to: Dr. F. W. Nangole, P.O. Box 2212-00202, Nairobi, Kenya

\title{
PRESSURE ULCERS PRESENTATION AND MANAGEMENT AT KENYATTA NATIONAL HOSPITAL AND SPINAL INJURY HOSPITAL
}

\author{
F.W. NANGOLE, S.O. KHAINGA and J. KIBOI
}

\begin{abstract}
Objective: To determine the presentation and management of patients with pressure ulcers.

Design: A prospective study.

Setting: The Kenyatta National Hospital (KNH) and National Spinal Injury Hospital (NSIH).

Subjects: One hundred and thirteen patients were evaluated. Ninety six patients from KNH and seventeen from NSIH. Patients admitted at Kenyatta National Hospital and National Spinal Injury Hospital with pressure ulcers during the study period.

Results: Of the 113 patients, $77(68.1 \%)$ were male and 36 (31.9\%) were female. Mean age of the patients studied was 38.1 years while the range was between 12 and 74 years. Paraplegia was the main associated medical condition accounting for $35.4 \%$, followed by HIV/AIDS with $27.4 \%$. The most common anatomical site for pressure ulcers was tronchanteric region with $43 \%$ of the ulcers. Pressure ulcers of grade III and IV accounted for $66.4 \%$ of the ulcers. Two hourly turning was the most common method of pressure dispersion used. Gauze dressing was the most common method used in wound care while $67.3 \%$ of the patients had their wounds cleaned with povidoneiodine. Fasciocutaneous flaps were the most common surgical procedure performed $(81.7 \%)$ for closure of pressure ulcers. Overall, $59.3 \%$ of surgical procedures had been successful at one month. This was, however, reduced to $48.1 \%$ at three months.

Conclusion: Majority of patients with pressure ulcers were in a relatively young age group with a mean age of 38 years. Most of the ulcers were located along bony prominence points of the pelvic girdle and the proximal femur. Most of the ulcers in this study were treated conservatively, with only a few ulcers subjected to surgical interventions. For the ulcers treated with surgical interventions the early outcome was good, however studies need to be done to determine long term outcomes.
\end{abstract}

\section{INTRODUCTION}

Pressure ulcer is a serious and common condition that spreads across all the medical disciplines. It is more common among the debilitated patients. While the above is so, the management of this condition has proved to be a nightmare to medical doctors, both in developed and developing countries. Despite the fact that there have been new developments in the management of wounds and patients as a whole, the outcome of pressure ulcers is by and large disappointing.

Despite recent advances in the management of pressure ulcers, the old saying that the best way to treat pressure ulcers is to anticipate its development and thus prevent its formation, still holds as it did before.

Little research, if any, of this condition seems to have been done locally. Statistics from elsewhere put the prevalence at $3-5 \%$ of all hospitalised patients (1). One may however, anticipate an increase in the prevalence of this condition due to a generally older population and an increase in terminal illnesses. Other factors such as Road Traffic Accidents (RTA) and HIV/AIDS may contribute to a high prevalence.

The management of this condition is expensive and time consuming and results more often than not 
a discouragement to the caregivers. The National Health Service (UK) spends an estimated 45 million sterling pounds each year on products and services directly relating to prevention and management of pressure sores (2). This is a colossal amount of money by any standards.

This study looked into the presentation and management of this condition at Kenyatta National Hospital (KNH) and National Spinal Injury Hospital (NSIH).

\section{MATERIALS AND METHODS}

This was a nine month descriptive prospective study from $1^{\text {st }}$ March to $31^{\text {st }}$ December 2002. The entry point was when the patient was first seen by the principal investigator. Patients who were put on medical treatment were followed up for three weeks to determine the treatment regimes and investigations that were carried out. All patients who underwent surgical intervention were followed up for three months so as to determine the outcome of their operations.

All adult patients admitted in the medical or surgical wards on treatment for pressure ulcers or pressure ulcers alongside other ailments during the defined period of study were recruited for the study.

All patients without pressure ulcers, paediatric patients, those with obstetric and gynaecological conditions and patients in the intensive care unit were excluded from the study.

The data collected included the data on patients demography, duration of hospital stay, current medical/surgical condition, anatomical sites of the ulcers, grades of the ulcers, type of treatment offered and outcome of surgical treatment.The ulcers were graded as follows:

Grade I ulcer limited to the epidermis and superficial dermis

Grade II ulcer involving skin and adipose tissues

Grade III ulcer extending through skin, adipose tissue and muscle

Grade IV ulcer involving bone or the joint

Patients were actively recruited for the study after meeting the inclusion criteria.

Thorough history and physical examination was undertaken on the recruited patients with special emphasis on pressure ulcers. Information on patients management was extracted from the files. Further information was obtained from interviews with doctors, nurses, physiotherapists and nutritionists of particular units.

All patients meant for surgery from the NSIH were transferred to plastic surgery unit, KNH. Post- operatively, all patients had their wounds assessed regularly up to the third post-operative month for outcome of the surgical procedure. All information gathered was then filled into pro-tested questionnaire. All questionnaires were coded and the collected data analysed.

Ethical approval was obtained from the research and ethics committee of KNH and informed consent from the patient or guardian.

\section{RESULTS}

The prevalence was determined between $10^{\text {th }}$ to $16^{\text {th }}$ November 2002. At KNH, a total of 1175 were evaluated. Of these 670 were in the medical wards, while 505 were in surgical wards. Of those in the medical wards, 29 had pressure sores giving a prevalence of $4.32 \%$. Among patients in the surgical wards, 20 patients had pressure sores giving rise to a prevalence of $3.96 \%$. Overall prevalence of pressure sores at $\mathrm{KNH}$ was $4.2 \%$.

At the National Spinal Injury Hospital (of the 25 patients present), 17 patients had pressure sores. This resulted in prevalence of $68 \%$. The overall prevalence of pressure sores among the patients in the hospitals was $5.5 \%$.

A total of 114 patients were recruited up during the study period. However 113 patients, 96 patients from KNH and 17 patients from National Spinal Injury Hospital were followed up to the completion of the study. One patient was excluded from the study due to the loss on follow up. The modal age group was 31-40 years. The age range was 12-74 years, with the mean age of presentation at 38.1 years. About $68 \%$ of the patients were male, while $32 \%$ of the patients were female giving rise to a male: female ratio of 2:1. Tronchanteric sores accounted for $43 \%$ of the ulcers while sacral and ischial ulcers contributed to $19.3 \%$ and $10.3 \%$ respectively only $2.8 \%$ of the ulcers were supraumbilical. The average number of ulcers per patient was 2.84. Grade III and IV contributed to $66.4 \%$ of the ulcers. Only $5.3 \%$ of the ulcers were grade I with $28.3 \%$ grade II. Of the 113 patients followed up, $35.4 \%$ were paraplegic with $9.7 \%$ of the patients quadriplegic. A significant proportion of the patients $(27.4 \%)$ had HIV / AIDS. Only $2.7 \%$ of the patients had dementia and 5.3\% diabetes mellitus. Overall $57.6 \%$ of the patients had stayed in hospital for duration of more than three months and $15.2 \%$ for duration of more than one year. The mean duration of hospital stay was 6.3 months.

Majority of the patients were treated conservatively (medical treatment). Table 1 illustrates the medical treatment the patients were subjected to. 
Table 1

Medical treatment

\begin{tabular}{|c|c|c|}
\hline & $\begin{array}{l}\text { No. of } \\
\text { Patients }\end{array}$ & $(\%)$ \\
\hline \multicolumn{3}{|l|}{ Investigation } \\
\hline Pus for culture/ sensitivity & 18 & 86.4 \\
\hline Tissue biopsies & 3 & 13.6 \\
\hline Radiographs & 0 & 0 \\
\hline Blood cultures & 0 & 0 \\
\hline \multicolumn{3}{|l|}{ Pressure dispersion method } \\
\hline Two hourly turning & 65 & 57.5 \\
\hline Ripple mattress & 14 & 12.4 \\
\hline Water in gloves & 4 & 3.5 \\
\hline None & 30 & 26.6 \\
\hline \multicolumn{3}{|l|}{ Dressing method } \\
\hline Gauze & 110 & 97.3 \\
\hline Hydrogel & 3 & 2.7 \\
\hline \multicolumn{3}{|l|}{ Antiseptics } \\
\hline $\begin{array}{l}\mathrm{H}_{2} \mathrm{O}_{2} / \text { Normal } \\
\text { saline/Povidone-iodine } \\
\text { Normal saline/ }\end{array}$ & 21 & 18.6 \\
\hline Povidone-iodine & 55 & 48.7 \\
\hline $\begin{array}{l}\text { Normal saline and Rifocin } \\
\text { Normal saline/Honey/ }\end{array}$ & 10 & 8.8 \\
\hline Sugar & 15 & 13.3 \\
\hline Savlon & 6 & 5.3 \\
\hline Others & 6 & 5.3 \\
\hline \multicolumn{3}{|l|}{ Topical antibiotics } \\
\hline Silver sulphadiazine & 3 & 2.7 \\
\hline Metronidazole & 4 & 3.5 \\
\hline None & 106 & 93.8 \\
\hline \multicolumn{3}{|l|}{ Nutritional supplementation } \\
\hline Oral supplement & 4 & 3.5 \\
\hline Enteral tube feeding & 2 & 2.8 \\
\hline Parenteral feeding & 1 & 0.9 \\
\hline None & 106 & 93.8 \\
\hline \multicolumn{3}{|l|}{ Antispaciticity drugs used } \\
\hline Baclofen & 4 & 7.8 \\
\hline Diazepam & 4 & 7.8 \\
\hline None & 43 & 84.4 \\
\hline
\end{tabular}

A total of ten patients followed up during the study period had surgical procedures. Of these eight patients were paraplegic secondary to accidents; one had spinal bifida while one had head injury. The mean age for these patients was 37.5 years. The average duration of hospital stay was one year eight months. The range being 0.5 years -2 $3 / 4$ years.

About $58 \%$ of the ulcers operated on were tronchanteric, $23.1 \%$ were sacral, while $15.3 \%$ and $3.9 \%$ were ischial and calcaneal ulcers respectively. Overall $81.5 \%$ of the ulcers operated on were grade IV while $11 \%$ were grade III and $7.4 \%$ were grade II ulcers.

Table 2 demonstrates the surgical procedures done. At one month after surgery, about $59.3 \%$ of the surgeries done had taken fully, while $22.2 \%$ of operations had failed. Out of a total of 22 fasciocutaneous flaps done, 12 had taken fully $(54.4 \%)$ while five had failed. Myocutaneous flaps and V-Y plasty, one each had taken fully (Table 3).

Table 2

Surgical procedures done

\begin{tabular}{lcc}
\hline Procedure done & Frequency & $(\%)$ \\
\hline Skin graft & 2 & 7.4 \\
Primary closure & 1 & 3.7 \\
Fasciocutaneous flaps & 22 & 81.5 \\
Myocutaneous flaps & 1 & 3.7 \\
V-Y plastys & 1 & 3.7 \\
Others & 0 & 0 \\
\hline Total & 27 & 100 \\
\hline
\end{tabular}

Table 3

Outcome of surgery at one month after surgery

\begin{tabular}{lcccc}
\hline Procedure done & $\begin{array}{c}\text { Full take } \\
\text { frequency }\end{array}$ & $\begin{array}{c}\text { Outcome } \\
\text { partial take } \\
\text { frequency }\end{array}$ & $\begin{array}{c}\text { Failed } \\
\text { frequency }\end{array}$ & Total \\
\hline Skin graft & 1 & 0 & 1 & 2 \\
Primary closure & 1 & 0 & 0 & 1 \\
Fasciocutaneous flaps & 12 & 5 & 5 & 22 \\
Myocutaneous flaps & 1 & 0 & 0 & 1 \\
V-P plastys & 1 & 0 & $6(22.2)$ & $27(100)$ \\
\hline Total $(\%)$ & $16(59.3)$ & $5(18.6)$ & 0 \\
\hline
\end{tabular}


At three months after surgery $48.1 \%$ of the surgical procedures done had still taken fully, while $33.4 \%$ had failed (Table 4).

Table 4

Outcome of surgery at three months after surgery

\begin{tabular}{lcccc}
\hline $\begin{array}{l}\text { Procedure } \\
\text { done }\end{array}$ & Fulltake & $\begin{array}{c}\text { Partial } \\
\text { take }\end{array}$ & Failed & Total \\
\hline Skin graft & 1 & 0 & 1 & 2 \\
Primary closure & 0 & 0 & 1 & 1 \\
Fasciocutaneous flaps 10 & 5 & 7 & 22 \\
Myocutaneous flaps & 1 & 0 & 0 & 1 \\
V.Y Plasty & 1 & 0 & 0 & 1 \\
\hline Total (\%) & $13(48.1)$ & $5(18.5)$ & $9(33.4)$ & 27 \\
\hline
\end{tabular}

\section{DISCUSSION}

The point prevalence of pressure ulcers at $\mathrm{KNH}$ was $4.2 \%$, while that at National Spinal Injury Hospital was $68 \%$ with an overall of $5.5 \%$. This compares well with the study carried out by Young et al (1) who demonstrated a prevalence of 3-5\% of all hospitalised patients. However, other studies have quoted a higher prevalence rate with Lepisto and Errickson (3) quoting a prevalence of up to $6.4 \%$, Amlung (4) in a national pressure survey found a prevalence of $14.8 \%$.

In spinal injury patients, a prevalence of between $25-85 \%(4,5)$ has been quoted in literature. It is therefore not surprising that the prevalence at the National Spinal Injury Hospital was $68 \%$. More than $90 \%$ of the patients studied were less than 60 years of age. The mean age of presentation was 38.1 years. This contrasts with studies done elsewhere. Thoroddseu (6) in a consecutive sample of 3,048 patients had a mean age of 75 years. More than $80 \%$ of the patients in his study were more than 70 years of age.

The reason could be that while HIV / AIDS and spinal injury were the main medical conditions in our patients, in the developed world, it is mainly stroke and dementia that accounts for most of the cases with the pressure sores. These do occur in elderly patients.

Of the patients studied $68.1 \%$ were male patients, while only $31.9 \%$ were females. This gives male to female ratio of 2:1. The most probable reason for this is that the male population is more prone to injuries as opposed to the females due to the mobile nature of lifestyle. Astudy carried outbySpector(7)demonstrated that male patients were at a more risk of pressure sore development than femaleones. Bergquistand Frontz (8) also demonstrated that males were more predisposed to pressure ulcer development than females.
About $60 \%$ of the patients had stayed in hospital for a duration greater than three months. The range of hospital stay was between two weeks and three years with an average duration of stay of 6.3 months. The average duration of hospital stay among patients studied seemed to be lower than what has been found in other studies. Astudy carried out by Heinmann (9) demonstrated a mean duration of hospital stay of 307 days (approximately ten months) with a median of 123 days (approximately four months). The maximum duration of hospital stay was six years.

Of the patients studied $35.4 \%$ of the patients were paraplegic while HIV / AIDS contributed to $27.4 \%$. Dementia, diabetes mellitus and cerebrovascular accidents had a combined contribution of only $10.7 \%$. This is in sharp contrast to the Western world where two thirds of the patients with pressure sores either have accidents or dementia (10).

A total of 321 ulcers were encountered during the study. The average number of ulcers per patient was 2.84. This is in keeping with a study carried by Jaul (10) who demonstrated an average of 2.8 ulcers per patient.

Grades III and IV accounted for $66.4 \%$ of the ulcers. Sacral, ischial and trochanters accounted for a total of $72.6 \%$ of the ulcers. Overall $97.2 \%$ of the ulcers were below the umbilicus. This is in keeping with most studies, which demonstrate that upto $90 \%$ of the ulcers are below the umbililicus $(3,6,10)$.

Only $5.3 \%$ of the ulcers were grade I. Lepisto and Errickson(3) in their study demonstrated that most of the ulcers were grade II. In this study grade II ulcers were $28 \%$. Heinmann (9) demonstrated in his study that upto $50 \%$ of the ulcers were grade I, with grades II and III contributing to a total of 38\%. Grade IV in his study contributed to $12 \%$ as compared to $24 \%$ in this study. An apparent low prevalence of grade I ulcers in this study could be as a result of dark skinned patients that were mainly encountered. It is much easier to demonstrate a grade I lesion in a light skinned individual as opposed to a dark skinned person.

Out of a total of 321 ulcers, only $22(6.85 \%)$ had any investigations done. Of these 19 had pus for culture and sensitivity, while only three had tissue biopsy for culture and sensitivity. No radiological investigations were done. The role of radiological investigations in pressure sore is significant in ruling out bone infection $(11,12)$. Studies done by Esposito and Ziccardo (13) demonstrated validity of modern CT scanning as a main diagnostic method.

Pressure dispersion is a fundamental principlein the management of pressure sores. Several pressure dispersion methods have been in use over the years. The most common pressure dispersion method employed was two hourly turning of patients $(57.5 \%)$ 
while $12.4 \%$ of the patients were on ripple mattresses. A significant proportion of patients (26.6\%) had no pressure dispersion method employed. A small proportion of patients $(3.5 \%)$ had water filled gloves employed in prevention of calcaneal sores. Sharp and Burr (14) in their study on pressure ulcer prevention and care in Australia, also demonstrated this method in use. Two hourly turning as pressure dispersion method is a method that needs a lot of motivation and morale by the staff and the patients for it to be successful. It is labour intensive and time consuming.

Of the dressing methods employed, $97.3 \%$ of the patientshad their wounds dressed with gauzedressing materials. Only $2.7 \%$ of the patients were dressed with hydrogels. Most studies have demonstrated gauze dressing to be more expensive and time consuming as compared to either hydrocolloids or hydrogels (15-17). Hydrogel dressings maintains moisture in the wounds which encourages epithelialisation and hence rapid wound healing (18).

The most commonly used antiseptic was providone-iodine contributing to $67.3 \%$ of the antiseptics used to clean wounds. A significant number of patients' wounds, $(13.3 \%)$, were cleaned and dressed with either honey or sugar. However, there was no criteria whatsoever at both hospitals as to which antiseptics to use. The use of honey or sugar as a method of treatment for wounds has been widely used and quoted in literature (19).

Only $6.2 \%$ of the patients had topical antibiotics applied to their wounds, of this silversulphadiazine contributed to $42.8 \%$, while metronidazole ointment to $57.2 \%$. This is consistent with a study carried out by Kucan in 1981 (20) who demonstrated that silversulphadiazine was one of the most commonly used topical antibiotics.

Of the patients studied $93 \%$ had no topical antibiotics used. This is also consistent with most studies, which discourage indiscriminate use of topical antibiotics (21). Topical antibiotics should only be used after culture and sensitivity results and only for a short duration so as to prevent bacterial resistance. Most antibiotics may be cytotoxic to fibroblasts and may impair healing.

About $94 \%$ of the patients had no nutritional support. Most studies have demonstrated that nutritional support positively influences the rate of pressure ulcers healing $(22,23)$. An adequate nutritional diet with emphasize on both macro and micronutrients must be put in place.

The mean age of the patients operated on was 37.5 years. Of the ulcers operated on $57.7 \%$ were trochanteric while $23.1 \%$ were sacral sores. The most common ulcer grade operated on was grade IV $(81.5 \%)$. Fasciocutaneous flaps was the most common surgical procedure (81.5\%). Myofasciocutaneous flaps contributed to $3.7 \%$ of the operations with skin grafts $7.4 \%$. About $60 \%$ of the surgical procedures done had taken fully at one month after surgeries. This had however decreased to $48.1 \%$ at three months after surgery.

Outcomes of surgical management of pressure sore have varied from different studies. The underlying medical / surgical conditions, the patients' age, as well as the aggressiveness of pressure dispersion influences the success rates. Jiburum and Achebe (24) who operated on 28 patients with 61 pressure sores, 29 of which were trochanteric reported a success rate of $72.1 \%$. They recommended the use of tensorfascia lata for the trochanteric sores.

Guisenoff (25) reported a success rate of 59\% at 12 months of follow up. He reported very good results with the use of tensor fascia lata flap for the treatment of the trochanteric sores.

\section{RECOMMENDATIONS}

Prevention is key to pressure ulcer management. The preventive measures involves recognition of high risk patients, early detection of incipient pressure sores and aversion of ulcer formation. Each institution must therefore put in place a risk assessment system that would identify high risk patients, such as the Braden scale (26). Special nursing care and pressure dispersion methods would then be directed to this patients thus preventing ulcer formation. In the event of inadequate nursing staffs, relatives should be trained and allowed to assist in two hourly turning of the patients.

There is a need to improve on wound management as a whole. The starting point could be continuous medical education to the care givers on wound care and dressing materials. Hospitals should also acquire modern dressing materials and ensure that they are readily available for use.

Surgical management is critical in the management of grade III and IV ulcers. Patients with this ulcers should be subjected to early surgical management to ensure prompt wound closure. This would also reduce the overall hospital stay hence reducing on the cost.

Nutritional support is a critical element in pressure ulcer management and wound care in general. There must thus be a strong nutritional support team in place to ensure a good nutritional environment for wound healing.

\section{ACKNOWLEDGEMENTS}

To the medical personnel of both NSIH and KNH for their support during this research. 


\section{REFERENCES}

1. Young, J. B. and Dobrzanski, S. Pressure sores epidemiology and current management concepts. Drugs Aging. 1992; 2: 42-57.

2. Forrest, S.A. Research to inform the strategic management of supply in pressure sore area care. J. Tissue Viability. Engl. 2001; 11: 20.

3. Lepisto, M. and Errickson, E. Patients with pressure ulcers in Finnish hospitals. Intern J. Nurs. Pract. 2001; 7: 280-287.

4. Amlung, S.R. National pressure ulcers prevalence survey, a benchmarking approach. Advances in skin and Wound care (USA). 2001; 48: 26.

5. Davis, C. M. and Caseby, N.G. Prevalence and incidence studies of pressure ulcers in two long term care facilities in Canada. Ostomy/wound Management. 2001; 47: 28-34.

6. Thoroddseu, A. Pressure sore prevalence a national survey. J. Clin. Nurs. 1999; 8: 170-179.

7. Spector, W.D. Correlates of pressure sores in nursing homes: Evidence from the National Medical Expenditure Survey. J. Invest. Dermatology. 1994; 102: 42-45.

8. Bergquist, S. and Frantz, R. Pressure ulcers in community based older adult receiving home health care. Prevalence, incidence and associated risk factors. Advances in Wound Care. 1999; 12: 339-351.

9. Heinmann, A. Decubitus ulcers in the terminal phase. Dtsch. Med. Wonchenschr. 2000; 125: 45-51.

10. Jaul, O. Pressure sores a one year study. Harefual. 2001; 140: 903-906.

11. Hendrix, R.W. and Calenoff, L. Radiology of pressure sores. Radiology. 1981; 38: 351-356.

12. Badley, R. Imaging in chronic spinal injury-medication and benefits. Eur. I. Radiol. 2002; 42: 135-153.

13. Esposito, G. Ziccardo, P. and Multiple, C. T. Imaging in pressure sores. Plast. Recon. Surg. 1994; 2: 333-342.

14. Sharp, C. and Burr, G. Pressure ulcer prevention and care, a survey of current practice. J. Qual. Clin. Pract. 2000; 20: 150-157.
15. Chang, K.U. and Alsagoffs. Randomised control trial comparing hydrocolloid and saline gauze dressing. Med. J. Malaysia. 1998; 53: 428-431.

16. Williams, C.An investigation of the benefits of aquacel hydrofibre wound dressing. Brit. J. Nurs. 1999; 8: 676-679.

17. Kraft, M.R. and Lawson, L. Comparison of epi lock and saline dressings in the treatment of pressure ulcers. L. Decubitus. 1993; 6: 42-46.

18. Capilla, S. and Perez, R. Comparison of the effective and cost of treatment with humid environment as compared to traditional care. Torra:Bon je Revisita de enfemeria. 2000; 23: 17-24.

19. Zeno, N. and Chicariki. Pressure sores in the elderly. Geriatric surgery, comprehensive care of the elderly patient. 3rd ED. (1990), Urban and Scwarzenenberg, Baltimore-Munich. 549-551.

20. Kucan, J.O. Comparison of dermazine, povidone -iodine and physiological saline in the treatment of chronic pressure sores. J. A. M. Geriatric Societry. 1981; 29: 232.

21. Galdin, J.E. Sepsis associated with decubitus ulcer. Amer. J. Med. 1976; 61: 436.

22. Flanigan, K.H. Nutritional aspect of wound healing. Adv. Wound Care. 1997; 10: 48-52.

23. Himes, D. Nutritional supplements in the treatment of pressure ulcers. Adv. Wound care. 1997; 10: 30-31.

24. Jiburum, B. S. and Achebe, J.U. Early results of operative closure of pressure sores in traumatic paraplegics. Intern. Surg. 1995; 80: 178-180.

25. Guisenoff, J. A. Outcome for surgical coverage of pressure sores in non-ambulatory non-paraplegic elderly patients. Ann. Platy. Surg. 2002; 48: 633-640.

26. Bergstrom, N., Braden, B., Kemp, M. and Champagen, M. Predicting Pressure ulcer risk. A multisite study of the predictive validity of the Braden scale. Nurs. Res. 1998; 47: 261-269. 